\title{
O sigilo do prontuário médico como um direito essencial do paciente: uma análise a partir das normativas do Conselho Federal de Medicina
}

The confidentiality of medical record as an essential right of the patient: an analysis based on the regulations of the Federal Council of Medicine, Brazil

La confidencialidad del registro médico como un derecho esencial del paciente: un análisis a partir de las normativas del Consejo Federal de Medicina, Brasil

\author{
Ana Thereza Meireles Araújo ${ }^{1}$ \\ Itanaina Lemos Rechmann² \\ Thayná Andrade Magalhães ${ }^{3}$
}

\begin{abstract}
Resumo
Objetivo: avaliar a condição de sigilo do prontuário médico a partir da perspectiva do direito do paciente, considerando as normativas vigentes no país emanadas do Conselho Federal de Medicina. Metodologia: a pesquisa tem natureza bibliográfica e documental, consubstanciando-se em livros e artigos da área jurídica, em legislação ordinária e resoluções do Conselho Federal de Medicina. Resultados: o prontuário médico é documento complexo, que apresenta caráter informativo e científico. Confidencialidade, sigilo e segurança das informações são princípios observados quando da divulgação das informações contidas no documento. Conclusão: o prontuário médico, seja físico, seja digital, mais do que uma ferramenta de trabalho dos médicos e instituições de saúde, é um direito do paciente e que se encontra acobertado pelo sigilo em respeito à intimidade do paciente.
\end{abstract}

Palavras-chave: Registros médicos. Direitos do paciente. Confidencialidade. Legislação sanitária.

\begin{abstract}
Objective: to evaluate the confidentiality condition of the medical record from the perspective of the patient's right, considering the regulations in force in the country emanating from the Federal Medical Council, Brazil. Methodology: the research has bibliographic and documentary nature, in books and articles of the legal area, in ordinary legislation and resolutions of the Federal Council of Medicine, Brazil. Results: medical records are complex documents, which are informative and scientific. Confidentiality,

\footnotetext{
${ }^{1}$ Doutora em Relações Sociais e Novos Direitos pela Universidade Federal da Bahia (UFBA). Professora da Pósgraduação em Direito Médico da Universidade Católica do Salvador (UCSal). E-mail: anatherezameirelles@gmail.com

${ }^{2}$ Especialista em Direto Público (UNIFACS). Pós-graduanda em Direito Médico e Bioética (UNIFACS). Bacharela em Direito (UNIFACS). Membro do Grupo de Pesquisa Vida (PPGD-UFBA), na área de Bioética. Advogada no escritório Borel \& Prates Advogados Associados, com atuação em Direito Empresarial, Cível e do Consumidor. E-mail: thayna.magalhaesandrade@gmail.com

${ }^{3}$ Pós-graduanda em Direito Médico e Bioética (UNIFACS). Bacharela em Direito (UNIFACS). Advogada no escritório Novas Advocacia e Consultoria Jurídica, com atuação em Direito Civil e do Consumidor. E-mail: itana.rechmann@hotmail.com
} 
confidentiality and security of information are principles observed when disclosing the information contained in the document. Conclusion: Medical records, whether physical or digital, are more than a work tool of physicians and health institutions, it is a patient's right and is covered by secrecy with respect to the patient's intimacy.

Keywords: Medical records. Patient's rights. Confidentiality. Sanitary legislation.

\section{Resumen}

Objetivo: evaluar la condición de sigilo del prontuario médico desde la perspectiva del derecho del paciente, considerando las normativas vigentes en el país emanadas del Consejo Federal de Medicina, Brasil. Metodología: la investigación tiene naturaleza bibliográfica y documental, consubstanciándose en libros y artículos del área jurídica, en legislación ordinaria y resoluciones del Consejo Federal de Medicina, Brasil. Resultados: el prontuario médico es un documento complejo, que presenta carácter informativo y científico. Confidencialidad, confidencialidad y seguridad de la información son principios observados al divulgar la información contenida en el documento. Conclusión: el prontuario médico, ya sea físico, ya sea digital, más que una herramienta de trabajo de los médicos e instituciones de salud, es un derecho del paciente y que se encuentra encubierto por el sigilo en respeto a la intimidad del paciente.

Palabras clave: Registros médicos. Derecho del paciente. Confidencialidad. Legislación sanitária.

\section{Introdução}

A relação entre médico e paciente não apenas é disciplinada pelos Conselhos Federal e Regionais de Medicina, tem alcançado também o âmbito do Poder Judiciário e exigindo, em ambos os meios, seja para emissão de pareceres, seja para a resolução de litígios, o debate aprofundado acerca da responsabilidade médica, inclusive com a produção de provas, muitas vezes na forma de apresentação e verificação dos prontuários médicos.

O prontuário médico adquire relevância na relação entre médico e paciente, pois nele deve ser registrado todo o atendimento prestado ao paciente, incluindo informações acerca do seu estado de saúde, da evolução do tratamento, eventuais intercorrências, as medidas interventivas praticadas e o relatório de alta, sendo instrumento apto para definir a responsabilidade médica.

O prontuário médico é o acervo de informações relacionadas à saúde do paciente, produzido pelo profissional de saúde, e que pode consistir em principal instrumento de defesa do médico, permitindo aferir a observância das normas procedimentais e terapêuticas admitidas ao longo de todo o atendimento prestado. 
Muito embora seja intitulado prontuário médico, provocando a ideia de pertencer ao médico, trata-se de documento do paciente, e a ele pertence, haja vista que contém todas as informações da sua saúde. Não à toa, o prontuário médico, ainda que de responsabilidade do médico ou da instituição de saúde, é um direito do paciente resguardado pelo sigilo.

O presente artigo tem como principal objetivo caracterizar o prontuário médico como um direito do paciente resguardado pelo sigilo. Para tanto, será comentada a definição trazida na Resolução $n^{\circ}$ 1.638/2002, do Conselho Federal de Medicina (1), bem como serão identificados os tipos de prontuário médico, cotejando-se com a dimensão constitucional protetiva da pessoa, a partir da perspectiva do seu conteúdo principiológico.

O tema se assenta em importante justificativa na medida em que aponta para a necessidade de sedimentar o prontuário como um documento do paciente e resguardar a ele a natureza sigilosa, já que agrega conteúdos da individualidade e do curso da doença. Esta pesquisa abordará o direito do paciente ao prontuário médico à luz do Código de Ética Médica e das normativas do Conselho de Classe, e usará como caso central a situação da ex-primeira dama Marisa Letícia Lula da Silva.

A pesquisa tem natureza teórica, consubstanciando-se como um estudo bibliográfico e documental, na medida em que parte do levantamento é de normativas do Conselho Federal de Medicina, incluindo o Código de Ética Médica; da legislação vigente e da doutrina relacionada.

\section{Definição do prontuário médico à luz da Resolução CFM nº 1.638/2002}

O Conselho Federal de Medicina (CFM) possui, dentre outras competências, normatizar e fiscalizar o exercício profissional dos médicos e demais pessoas jurídicas que prestam a atividade da medicina.

De modo a fixar parâmetros para o exercício da referida função fiscalizadora, o CFM debruçou-se acerca do prontuário médico, fixando seu conceito, qualidade e finalidade na prática médica, por meio da Resolução $n^{\circ}$ 1.638/2002. Conforme o seu artigo $1^{\circ}$ (1), o prontuário médico é o documento que reúne as informações, sinais e imagens sobre a saúde do paciente.

Interessante registrar que a referida Resolução devota ao prontuário médico a qualidade de documento único, o que significa dizer que todas as informações pertinentes 
ao paciente, e sobre o serviço médico a ele prestado, estão nele reproduzidas, funcionando como uma espécie de acervo.

Depreende-se a importância do documento na medida em que resta claro a relevância das informações, caso a relação seja desdobrada em conflito jurídico. Compete ao profissional de saúde alimentar o prontuário com detalhamento e tecnicidade, a fim de que o mesmo possa revelar informações precisas e reais quanto à situação e aos tratamentos do paciente, titular do documento.

A unicidade do documento interessa ao próprio paciente e também aos seus familiares porque assegura a continuidade da assistência prestada, além de documentar a atuação do profissional. O prontuário médico é a prova da patologia do paciente e do seu tratamento. Essa qualidade interessa ainda ao médico e às instituições de saúde, pois garante o acesso ao histórico do paciente, evitando eventual desarmonia na comunicação entre a equipe profissional.

A documentação dos atos médicos possui relevância na prática médica, fazendo parte de capítulo específico do Código de Ética Médica (2). A documentação envolve a anamnese, exames de qualquer natureza, prescrição terapêutica, descrição de tratamento e medida interventiva, boletim de emergência, folha de internação, descrição de cirurgia, ficha anestésica, registro e pareceres, termo de consentimento informado, resumo de alta e atestado de óbito, todos preenchidos em data cronológica e com assinatura do médico (3).

A Resolução CFM n 1.638/2002 (1) destaca também que o prontuário médico possui natureza legal, sigilosa e científica. A natureza legal do prontuário médico está relacionada à natureza de prova no caso de responsabilidade civil, administrativa e penal. É possível afirmar que, na demanda judicial ou administrativa, o prontuário médico funciona como importante instrumento de defesa do médico, do hospital e sua equipe, pelo fato de reunir as informações pertinentes ao atendimento médico prestado, além de esclarecer como se deu o atendimento do paciente.

A Resolução destaca o direito do paciente de ver registradas informações de qualidade no prontuário médico e de ser preservada a informação nele contida, por meio da garantia do sigilo, bem como ser resguardada a sua intimidade (1). A existência desse direito do paciente exige do médico o dever de elaborar, preencher com letra legível, manusear e guardar o prontuário do paciente, documentando a sua atuação profissional. 
No ano de 2018, o Tribunal de Justiça do Estado do Rio de Janeiro produziu ementário cuja edição especial abarcou o tema erro médico, reunindo julgados que discutiram, entre outros assuntos, o prontuário médico e o dever de que seja redigido de forma transparente, precisa e objetiva (4).

A preocupação do CFM em destacar o caráter sigiloso do prontuário visa, sobretudo, preservar a intimidade do paciente, evitando exposições injustificadas, haja vista que todo o seu histórico de saúde e as suas intercorrências estarão consubstanciadas naquele documento, motivo pelo qual o seu acesso deve estar restrito àquele que demonstre interesse, como o próprio paciente, seus familiares e a equipe médica responsável.

Por fim, a Resolução CFM no 1.638/2002 registrou a natureza científica do prontuário médico, que pode ser objeto de estudo, discussão de casos e pesquisa pela comunidade médica e instituições de ensino, de modo a aperfeiçoar a prática médica e a pesquisa clínica, por meio da cura e da prevenção de doenças (1). Ressalta-se que tal possibilidade não pode ser o pressuposto para ignorar o dever de sigilo quanto à identidade do enfermo, permanecendo a necessidade de preservar a sua intimidade.

\section{Os tipos de prontuário médico: físico e digital}

O desenvolvimento da tecnologia da informação, a preocupação social com a responsabilidade ambiental e a necessidade de otimizar os espaços físicos contribuíram para o uso de plataformas digitais para a coleta e transmissão de dados. A atualidade impôs uma nova forma de produzir e guardar documentos por meio da digitalização. Essa realidade alcançou o prontuário médico, o qual é produzido e armazenado por meio físico e por meio digital.

Dentro dessa perspectiva, o CFM reconheceu a importância de utilizar os sistemas informatizados para a guarda dos dados descritos no prontuário médico como instrumento de modernização e melhoria no atendimento do paciente. Acrescente-se que essa possibilidade corrobora a segurança das relações médicas, na medida em que garante a manutenção perpétua das informações.

Assim, por meio da Resolução $n^{\circ}$ 1.821/2007, o CFM aprovou diretrizes concernentes à digitalização e ao uso dos sistemas informatizados para a guarda e o manuseio do prontuário médico, compatibilizando o crescente volume de documentos armazenados nas instituições de saúde (5). A garantia da confidencialidade e da 
segurança das informações na transformação do documento digital foi objeto de preocupação por parte do CFM, levando-o a aprovar, por meio de convênio com a Sociedade Brasileira de Informática, o Manual de Certificação para Sistemas de Registro Eletrônico em Saúde, que estabelece padrões nacionais e internacionais na área da saúde (artigo $1^{\circ}$ da Resolução CFM n 1.821/2007) (5).

As instituições de saúde devem, portanto, observar os padrões exigidos para a disponibilização e armazenamento eletrônico do prontuário médico, devidamente especificados pela própria Resolução CFM n $1.821 / 2007$, no seu artigo $2^{\circ}$, o qual estará submetido à aprovação de uma Comissão de Revisão de Prontuários, com competência para conceder selo de qualidade aos sistemas informatizados (5). Exige-se ainda o prazo mínimo de vinte anos, a partir do último registro, para a preservação do prontuário físico do paciente que não foi arquivado digitalmente.

Cumpre registrar que essa matéria passou a fazer parte da legislação federal a partir de dezembro de 2018, por meio da Lei n 13.787/2018, que dispõe sobre a digitalização e a utilização de sistemas informatizados para a guarda, o armazenamento e o manuseio de prontuário do paciente (6). Nota-se que a Lei $n^{\circ} 13.787 / 2018$ ratifica e se coaduna às diretrizes já contidas na Resolução CFM n 1.821/2007 (5), mantendo a coesão entre os diplomas, reforçando que o prontuário médico, seja em meio físico, seja em meio digital, deve ser objeto de especial atenção, por se tratar de um documento médico cujo paciente tem direito e também pelo fato de esse documento ser resguardado pelo sigilo.

\section{O direito do paciente ao prontuário médico}

De forma genérica, o prontuário médico pode ser entendido como o documento no qual constam as informações relativas ao histórico de saúde do paciente. Este tem o direito de acessá-lo, correspondendo, assim, ao médico ou à instituição de saúde o dever de fornecê-lo, inclusive explicando ao paciente as informações nele contidas de forma que possa compreendê-lo.

O artigo 88 do Código de Ética Médica veda ao médico "negar, ao paciente, acesso a seu prontuário, deixar de lhe fornecer cópia quando solicitada, bem como deixar de lhe dar explicações necessárias à sua compreensão, salvo quando ocasionarem riscos ao próprio paciente ou a terceiros" (2). 
Ressalta-se que também é dever do médico ser claro com o paciente no que tange às decisões concernentes ao seu tratamento. No âmbito da bioética, muito se discute sobre a preocupação quanto à capacidade de compreensão do paciente no curso da relação em voga. A compreensão é, pois, um elemento necessário à conformação de uma relação adequada.

O direito do paciente ao prontuário médico resta evidenciado na medida em que o Código de Ética Médica, em seu artigo 87, caput, determina que esse documento seja elaborado de forma que o paciente possa compreender, sendo, portanto, vedado ao médico "Deixar de elaborar prontuário legível para cada paciente" (2).

Assim, tem-se que cada prontuário médico, conterá o histórico de saúde do paciente por meio de escrita adequada à condição socioeconômica do paciente, ou seja, as informações contidas no prontuário médico devem ser transmitidas de forma tal a permitir que o paciente as assimile. Tal perspectiva corrobora a ideia trabalhada anteriormente, no sentido de que a compreensão da informação, hoje, deve ser um pressuposto a ser considerado pelo profissional. A normativa aponta para a necessidade de atentar para o dever de ser claro e preciso quanto à situação que envolve todas as questões do paciente.

O Código de Ética Médica, no capítulo que trata dos princípios fundamentais dispõe que "[...] XX - A natureza personalíssima da atuação profissional do médico não caracteriza relação de consumo". Sem embargo de eventual discussão acerca da aplicabilidade do microssistema de consumo à relação médico-paciente, o Código de Defesa do Consumidor, em seu artigo 72, assegura ao paciente o direito a acessar o seu prontuário médico, de modo que estará sujeito à pena de detenção de seis meses a um ano ou multa aquele que "impedir ou dificultar o acesso do consumidor às informações que sobre ele constem em cadastros, bancos de dados, fichas e registros" (7).

Embora o Código de Defesa do Consumidor não traga expressamente a figura do prontuário médico, entende-se que estes são contemplados pela norma na medida em que contém os registros de histórico de saúde do paciente, podendo, ainda, ser associado às fichas de saúde.

As normas ora citadas, inclusive, serviram de fundamento para o Conselho Nacional de Justiça reconhecer o direito do paciente ao prontuário médico e aprovar, na II Jornada de Direito da Saúde, o Enunciado 66 a seguir transcrito: 
Poderá constituir quebra de confiança passível de condenação por dano, a recusa imotivada em fornecer cópia do prontuário ao próprio paciente ou seu representante legal ou contratual, após comprovadamente solicitado, por parte do profissional de saúde, clínica ou instituições hospitalares públicos ou privados (8).

No caso do paciente falecido, muitas vezes os familiares suspeitam de erro médico e, com isso, queiram ter acesso ao prontuário ou, mesmo sem que paire tal suspeita, queiram saber o histórico de saúde do paciente, para melhor compreender do que ou por que ele morreu e, com isso, requeiram o prontuário junto ao médico ou instituição de saúde. É comum que o profissional ou a instituição de saúde fiquem receosos de fornecer o prontuário médico, já antevendo uma ação judicial de responsabilização por erro médico, por exemplo, e, diante desse fundado medo, neguem o fornecimento do prontuário do paciente falecido.

Independente do receio médico, e considerando que o prontuário é um documento que pertence ao paciente, o Conselho Federal de Medicina, no parecer CFM n. ${ }^{\circ}$ 06/10, reafirmando o direito ao sigilo, entende que este se projeta para além da morte do paciente, de modo que a liberação do prontuário médico, no caso de paciente falecido, fica adstrita à determinação judicial ou requisição pelos Conselhos de Medicina, não podendo ser fornecido diretamente aos parentes (9). Ocorre que a negativa do prontuário médico de paciente falecido chegou ao Poder Judiciário, o qual, por meio de concessão de tutela antecipada, determinou ao Conselho Federal de Medicina o fornecimento do prontuário médico quando solicitado por familiares, sob pena de multa diária de 50 mil reais.

Foi o que se deu nos autos da ação civil pública n. ${ }^{\circ}$ 0026798-86.2012.4.01.3500, em trâmite perante a $3^{a}$ Vara Federal de Goiânia, ajuizada pelo Ministério Público Federal em face do Conselho Federal de Medicina objetivando "lograr provimento judicial de conteúdo declaratório que assegure o acesso de familiares aos prontuários médicos de seus parentes falecidos" (10).

Diante dessa situação, o Conselho Federal de Medicina, destacando que o sigilo médico deve ser respeitado, editou a Recomendação CFM n. ${ }^{\circ} 3 / 14$ visando dar imediato cumprimento à referida decisão judicial, razão pela qual recomendou:

Art. $1^{\circ}$ - Que os médicos e instituições de tratamento médico, clínico, ambulatorial ou hospitalar: a) forneçam, quando solicitados pelo cônjuge/companheiro sobrevivente do paciente morto, e sucessivamente 
pelos sucessores legítimos do paciente em linha reta, ou colaterais até o quarto grau, os prontuários médicos do paciente falecido: desde que documentalmente comprovado o vínculo familiar e observada a ordem de vocação hereditária, e b) informem os pacientes acerca da necessidade de manifestação expressa da objeção à divulgação do seu prontuário médico após a sua morte (11).

$\mathrm{Na}$ ocasião, o Conselho Federal de Medicina interpôs Agravo de Instrumento $\mathrm{n}^{\circ}$ 0015632-13.2014.4.01.0000, distribuído para a Sexta Turma do Egrégio Tribunal Regional Federal da $1^{\text {a }}$ Região, sob a relatoria do Desembargador Federal Daniel Paes Ribeiro (12), o qual perdeu objeto por força do advento da sentença com efeito erga omnes na ação civil pública, mantendo a tese apresentada na decisão que deferiu a tutela antecipada, nos termos a seguir:

\begin{abstract}
$[\ldots]$
b.2) determino ao Conselho Federal de Medicina a adoção das devidas providências de orientação aos profissionais médicos e instituições de tratamento médico, clínico e ambulatorial ou hospitalar no sentido de: a) fornecerem, quando solicitados pelo cônjuge/companheiro sobrevivente do paciente morte, e sucessivamente pelos sucessores legítimos do paciente morto em linha reta, ou colaterais até o quarto grau, os prontuários médicos do paciente falecido, desde que documentalmente comprovado o vínculo familiar e observada a ordem de vocação hereditária; b) informarem os pacientes acerca da necessidade de manifestação expressa da objeção à divulgação do seu prontuário médico após a sua morte [grifo nosso] (12).
\end{abstract}

Em face dessa sentença, por prevenção, o Conselho Federal de Medicina interpôs recurso de apelação, distribuído por dependência em 07/11/2016, para o Desembargador Federal Daniel Paes Ribeiro, estando pendente de julgamento.

Considerando que o prontuário médico é um direito do paciente e que o Conselho Federal de Medicina é reticente ao fornecimento aos familiares, em caso de paciente morto, com fundamento no sigilo profissional e no artigo 89 do Código de Ética Médica (2), é permitido ao médico liberar cópias do prontuário apenas quando autorizado por escrito pelo paciente, para atender ordem judicial, ou para defender-se.

\title{
O sigilo das informações contidas no prontuário médico e a Lei Marisa Letícia
}

O Código de Ética Médica traz o sigilo como um de seus princípios fundamentais, redigido da seguinte forma: "[...] XI - O médico guardará sigilo a respeito das informações 
de que detenha conhecimento no desempenho de suas funções, com exceção dos casos previstos em lei" (2).

Antes mesmo da existência do citado Código ou da reprodução do sigilo pelos Conselhos Regionais de Medicina, o Juramento de Hipócrates - tradicional à formatura do curso de Medicina -, embora não traga expressamente a palavra sigilo, a ele referencia, ainda que de forma embrionária, como um dever de cuidado do médico de abster-se de divulgar desnecessariamente informações de seu conhecimento: "[...] Àquilo que no exercício ou fora do exercício da profissão e no convívio da sociedade, eu tiver visto ou ouvido, que não seja preciso divulgar, eu conservarei inteiramente secreto" (13).

O sigilo profissional é de relevância ímpar, de modo que o Código de Ética Médica Ihe dedica todo o capítulo IX, o que compreende do artigo 73 ao 79. Para a discussão ora em voga, interessa precisamente o artigo 73.

De acordo com o artigo 73 do Código de Ética Médica (2), excetuadas as situações de motivo justo - cujo Código não elenca nem exemplifica o que vem a ser -, dever legal, ou nas quais o paciente consentiu por escrito, é proibido ao médico divulgar fato que seja de seu conhecimento em virtude do exercício da profissão, mesmo que esse seja de conhecimento público ou que o paciente já tenha falecido.

Tendo em vista o citado artigo do Código de Ética Médica, cumpre rememorar que em janeiro de 2017 foi noticiado o caso da ex-primeira dama Marisa Letícia Lula da Silva, que teve informações médicas veiculadas em grupo de rede social. Inclusive, à época, a médica suspeita de repassar tais informações foi dispensada por justa causa pelo hospital e, posteriormente, ingressou com ação judicial perante o Tribunal Regional do Trabalho da $2^{a}$ Região, o qual condenou o hospital a indenizá-la por danos morais no valor de $R \$$ $577.200,00$ - cerca de vinte vezes o último salário da médica (14).

Em suma, a defesa do hospital, conforme foi noticiado, aduziu que a dispensa por justa causa se deu pelo fato de a médica supostamente ter rompido o contrato de trabalho, na medida em que este "[...] estabelece que o empregado não pode revelar ou divulgar informação a terceiros de que tenha conhecimento ou acesso no hospital" (15).

Diante desse fato, o deputado Jorge Solla (PT-BA), observando que o popular vazamento de prontuário médicos, incluindo exames e imagens de pacientes, são punidos apenas pelos conselhos profissionais, segundo as diretrizes do Código de Ética Médica, apresentou em março de 2017 o Projeto de Lei nº 7.237-A/2017 (Lei Marisa Letícia) com a 
proposta de acrescer ao Código Penal o artigo 153-A, "[...] que trata da divulgação não autorizada de imagens e dados de prontuários de pacientes sob cuidados de profissionais de saúde" (15).

Em apenso a esse projeto, se encontra o Projeto de Lei $n^{\circ}$ 8.480/2017, da autoria do deputado Victor Mendes (PSD-MA), o qual propõe o acréscimo de parágrafo ao artigo 154 do Código Penal, que trata da violação do segredo profissional, com o intuito de aumentar a pena nos termos a seguir:

[...] de um sexto a um terço quando a revelação de segredo consistir na divulgação de informações médicas, constantes de prontuários, exames, cadastros ou requisições pertencentes aos bancos de dados de hospitais, clínicas ou laboratórios, ou fotos e vídeos de pacientes em atendimento. (16)

O parecer da Comissão de Seguridade Social e Família, em 28/11/2018, sob a relatoria da deputada Jandira Feghali, foi pela aprovação dos Projetos de Lei anteriormente mencionados, acrescendo o artigo 153-A ao Código Penal nos termos abaixo4:

Art. 153-A Divulgar alguém que tenha acesso a pacientes sob cuidados de profissionais de saúde ou a seu prontuário, sem justa causa e sem prévia autorização, imagens do paciente, dados do seu prontuário ou informações relacionadas a exames solicitados:

Pena - detenção, de três meses a um ano, e multa.

$\S 1^{\circ}$ A pena será de um a quatro anos de detenção, e multa, se o responsável pela divulgação for profissional de saúde ou qualquer outro profissional que tiver contato com o paciente em razão de função, ministério, ofício ou profissão.

$\S 2^{\circ} \mathrm{O}$ disposto no caput não se aplica quando a divulgação possui fins acadêmicos, jornalísticos, judiciais e de investigação criminal, devendo, nos casos acadêmicos e jornalísticos ser assegurada a não identificação do paciente.

$\S 3^{\circ}$ Somente se procede mediante representação.(16)

Além das diretrizes do Código de Ética Médica e da tipificação no Código Penal (ou, ainda, dos citados Projetos de Lei), o sigilo encontra amparo na Constituição Federal, notadamente no art. $5^{\circ}$, inciso $X$, porquanto "[...] são invioláveis a intimidade, a vida privada, a honra e a imagem das pessoas [...]" (17), de modo que, em sendo a relação

\footnotetext{
${ }^{4} \mathrm{Em}$ atendimento às formalidades de que trata o Regimento Interno da Câmara dos Deputados, notadamente o artigo 105, o Projeto de Lei ${ }^{\circ} 7.237-A / 2017$ foi arquivado no dia 31/01/2019 e, em sequência, no dia 12/02/2019, o deputado Jorge Solla apresentou requerimento de desarquivamento de proposições, dentre as quais o mencionado Projeto de Lei.
} 
médico-paciente pautada na confiança, deve ser preservado o sigilo do prontuário médico e das informações nele contidas.

\section{Considerações finais}

O Código de Ética Médica, ao normatizar o exercício da profissão do médico, seja atividade de ensino, pesquisa ou administração da saúde, ou qualquer outra de que se utilize o conhecimento advindo do estudo da Medicina, traz, como um de seus princípios, o sigilo, o qual o médico deverá guardar acerca das informações que são de seu conhecimento por força do exercício da profissão, ainda que o fato seja de conhecimento público ou que o paciente tenha falecido.

Excepcionalmente, em respeito ao princípio da legalidade, o dever de sigilo poderá ser mitigado, como nos casos em que o próprio paciente, por escrito, consente com o fornecimento da informação, por dever legal ou por justo motivo, este aferível in casu, na medida em que o Código de Ética Médica não elencou, ainda que exemplificativo, de quais seriam esses motivos, causando, assim, insegurança para a prática médica.

Por ser o sigilo um princípio que norteia a atividade médica, este se estende aos documentos médicos, inclusive o prontuário, seja físico ou digital. Em relação ao prontuário médico, é vedado ao médico permitir que pessoas não obrigadas ao sigilo profissional possam manuseá-lo ou ter conhecimento do seu conteúdo.

É vedado ao médico liberar cópias do prontuário sem autorização, por escrito, do paciente, salvo se para atender ordem judicial; requisição do Conselho Regional de Medicina; ou para a sua própria defesa, caso em que o médico deverá solicitar a observância do sigilo profissional.

Entende-se, para maior segurança da prática médica e em respeito à intimidade do paciente, que o sigilo das informações contidas no prontuário médico permanece mesmo após o falecimento do paciente, de modo que os familiares, caso queiram ter acesso a esse documento, deverão solicitar pela via judicial ou administrativamente por meio de consulta ao respectivo Conselho Regional de Medicina, indicando em ambos os casos as questões que pretendem ver respondidas a partir daquele documento e a finalidade do acesso, que não pode ser a mera curiosidade.

O prontuário médico, não obstante seja um documento médico de responsabilidade desse profissional (ou da instituição de saúde que assiste o paciente), é um documento do 
paciente, na medida em que deverá ser elaborado de forma legível para cada paciente, posto que contém dados clínicos que Ihe dizem respeito, não sendo permitido ao médico negar ao paciente o acesso ao seu prontuário, nem deixar de the fornecer cópia ou explicações acerca das informações nele contidas, salvo se disto puder resultar riscos ao próprio paciente ou a terceiros.

Assim, por ser o prontuário médico relevante, não apenas para o exercício da prática médica, mas, sobretudo, para o paciente, sendo um direito seu acessá-lo, ter conhecimento e compreender as informações nele contidas, e visando coibir condutas que possam vir a ferir este direito ou que não observem o dever de sigilo profissional, defendese a criminalização da divulgação do prontuário médico.

\section{Referências}

1. Conselho Federal de Medicina. Resolução $n^{\circ}$ 1.638/2002. Brasília, Distrito Federal, 9 de agosto de 2002. Disponível em: http://www.portalmedico.org.br/resolucoes/cFm/2002/ 1638_2002.htm [Acesso em 20 fev. 2019].

2. Conselho Federal de Medicina. Código de Ética Médica: resolução CFM n 2.217 , de 27 de setembro de 2018 (versão de bolso). Brasília: Conselho Federal de Medicina, 2018. $108 p$.

3. Prestes Júnior LCL. Canal médico. Disponível em: https://www.youtube.com/watch?v= RczW3EvpAa0 [Acesso em: 20 fev. 2019].

4. Rio de Janeiro. Tribunal de Justiça do Estado do Rio de Janeiro. Edição especial do Ementário de Jurisprudência Cível: erro médico. Rio de Janeiro, 14 jan. 2019. Disponível em: http://conhecimento.tjrj.jus.br/noticias/noticia/-/visualizar-conteudo/5736540/6115462 [Acesso em 28 fev. 2019].

5. Conselho Federal de Medicina. Resolução $n^{0}$ 1.821/2007. Brasília, Distrito Federal, 23 de novembro de 2007. Disponível em http://www.portalmedico.org.br/resolucoes/cFm/2007/ 1821_2007.pdf [Acesso em 21 fev. 2019].

6. Brasil. Lei no 13.787, de 27 de dezembro de 2018. Dispõe sobre a digitalização e a utilização de sistemas informatizados para a guarda, o armazenamento e o manuseio de prontuário de paciente. Diário Oficial da República Federativa do Brasil, Brasília, DF, 28 dez. 2018. Disponível em: http://www.planalto.gov.br/ccivil_03/_ato2015-2018/2018/ lei/L13787.htm [Acesso em 16 fev. 2019]. 
7. Brasil. Código de Defesa do Consumidor. Lei n. ${ }^{\circ} 8.078$, de 11 de setembro de 1990. Dispõe sobre a proteção do consumidor e dá outras providências. Brasília, 11 de setembro de 1990. Publicado no Diário Oficial da União de 12 de setembro de 1990 e retificado em 10 de janeiro de 2007. Disponível em: http://www.planalto.gov.br/ccivil_03/Leis/L8078 compilado.htm [Acesso em: 11 fev. 2019].

8. Conselho Nacional de Justiça. II Jornada de Direito da Saúde. A Justiça faz bem à Saúde. Disponível em: http://www.cnj.jus.br/files/conteudo/destaques/arquivo/2015/ 05/96b5b10aec7e5954fcc1978473e4cd80.pdf [ Acesso em: 11 fev. 2019].

9. Conselho Federal de Medicina. Proibida liberação de prontuário de paciente falecido. Brasília, Distrito Federal, 21 de março de 2010. Disponível em: https://portal.cfm.org.br /index.php?option=com_content\&view=article\&id=9703:\&catid=3 [Acesso em: 14 fev. 2019].

10. Brasil. Tribunal Regional Federal da $1^{\text {a }}$ Região. Ação Civil Pública n. ${ }^{\circ} 0026798$ 86.2012.4.01.3500 distribuída para a $3^{\text {a }}$ Vara de Goiânia. Juiz: Leonardo Buissa Freitas. Processo físico. Sentença incluída em 08/04/2016.

11. Conselho Federal de Medicina. Recomendação CFM no 3/14. Brasília, Distrito Federal, 28 de março de 2014. Disponível em: https://portal.cfm.org.br/images/Recomendacoes/ 3_2014.pdf [Acesso em: 11 fev. 2019].

12. Conselho Federal de Medicina. Agravo de Instrumento n. ${ }^{\circ}$ 0015632-13.2014.4.01.0000 distribuído para a Sexta Turma do Egrégio Tribunal Regional Federal da $1^{\mathrm{a}}$ Região.

13. Conselho Regional de Medicina do Estado de São Paulo. Juramento de Hipócrates. Disponível em: https://www.cremesp.org.br/?siteAcao=Historia\&esc=3 [Acesso em: 13 fev. 2019].

14. Brandino G. Sírio é condenado a indenizar médica suspeita de vazar informações de Marisa Letícia. Folha de S. Paulo, São Paulo, 13 abr. 2018. Disponível em: https://www1.folha.uol.com.br/poder/2018/04/sirio-e-condenado-a-indenizar-medicasuspeita-de-vazar-informacoes-de-marisa-leticia.shtml [Acesso em: 13 fev. 2019].

15. Brasília. Câmara dos Deputados. Projeto de Lei n. ${ }^{\circ}$ 7.237-A/2017. Altera o Decreto-Lei $\mathrm{n}^{\circ}$ 2.848, de 7 de dezembro de 1940 (Código Penal), para acrescer-lhe o art. 153-A, que trata da divulgação não-autorizada de imagens e de dados de prontuários de pacientes sob 
cuidados de profissionais de saúde. Apensado ao Projeto de Lei n. ${ }^{\circ}$ 8.480/2017. Disponível em: https://www.camara.leg.br/proposicoesWeb/fichadetramitacao?idProposicao= 2127461\&ord=1 [Acesso em: 13 fev. 2019].

16. Brasil. Projeto de Lei $.^{\circ} 8.480 / 2017$, da autoria do deputado Victor Mendes (PSD-MA).

17. Brasil. Constituição da República Federativa do Brasil de 1988. Brasília, 05 de outubro de 1988. Disponível em: http://www.planalto.gov.br/ccivil_03/Constituicao/

Constituicao.htm [Acesso em: 14 fev. 2019].

Como citar esse artigo:

Araújo ATM, Rechmann IL, Magalhães TA. O sigilo do prontuário médico como um direito essencial do paciente: uma análise a partir das normativas do Conselho Federal de Medicina. Cadernos Ibero-Americanos de Direito Sanitário. 2019 jan./mar.; 8(1): 95-109. 